\title{
Bone Glomus Tumor
}

National Cancer Institute

\section{Source}

National Cancer Institute. Bone Glomus Tumor. NCI Thesaurus. Code C6480.

A benign or malignant glomus tumor arising from the bone. 